\title{
Effect of Ce substitution on Structural and Superconducting Properties of Bi-2212
} textured composites

\author{
C.Kaya ${ }^{\mathrm{a}}$, B. Özçelik ${ }^{\mathrm{a} *}$, B. Özkurt ${ }^{\mathrm{b}}$, A. Sotelo ${ }^{\mathrm{c}}$, M. A. Madre ${ }^{\mathrm{c}}$ \\ ${ }^{a}$ Department of Physics, Faculty of Sciences and Letters, Çukurova University. 01330 \\ Adana, Turkey \\ ${ }^{\mathrm{b}}$ Department of Electronic and Computer Education, Faculty of Tarsus Technical \\ Education, University of Mersin, Mersin/Turkey \\ c ICMA (CSIC-Universidad de Zaragoza). María de Luna, 3. 50018 Zaragoza, Spain.
}

\begin{abstract}
In this study, $\mathrm{Bi}_{2} \mathrm{Sr}_{2} \mathrm{Ca}_{1-\mathrm{x}} \mathrm{Ce}_{\mathrm{x}} \mathrm{Cu}_{2} \mathrm{O}_{\mathrm{y}}$, where $\mathrm{x}=0,0.01,0.05,0.1$ and 0.25 , superconducting samples were prepared by solid state method and subsequently used as feed in a directional solidification process. The physical properties of the samples were investigated by powder X-ray diffraction, scanning electron microscopy (SEM), dcelectrical resistance, magnetization, and magnetic-hysteresis loops measurements. It has been found that no significant difference has been observed in the critical transition temperatures of samples except for the sample with the highest $\mathrm{Ce}$ additions, which shows the lowest $T_{c}$ compared with the other doped samples. Magnetic hysteresis measurements have shown that the hysteresis loop is greater than the doped samples. In addition, critical current density values obtained from the hysteresis loops measurements by using Bean's critical state model show a decrease with Ce-addition. All the results indicate that Cerium substitution for Ca produces the deterioration on the superconducting properties, compared with the undoped sample.
\end{abstract}

Keywords: Bi-based cuprates, XRD, SEM, Critical Current, M-H, LFZ-technique

*Corresponding Author: Tel./fax:+90.322.3386060/2496/+90.322.3386070

e-mail:ozcelik@cu.edu.tr 


\section{Introduction}

Since the discovery of superconductivity in the Bi-Sr-Cu-O system by Michel et al. [1] and the subsequent work reported by Maeda et al. [2] in $\mathrm{Bi}_{2} \mathrm{Sr}_{2} \mathrm{Ca}_{\mathrm{n}-1} \mathrm{Cu}_{\mathrm{n}} \mathrm{O}_{\mathrm{x}}(n=1,2,3)$ superconductor, there has been tremendous effort in order to improve the physical properties of BSCCO system. Both the fundamental research and industrial applications such as superconducting wires, tapes and thin films [3-5], one needs the isolation of a single phase of $\mathrm{Bi}-2223$ or $\mathrm{Bi}-2212$.

It is well known that according to chemical compositions, BSCCO system has three different phases with an ideal structural formula $\mathrm{Bi}_{2} \mathrm{Sr}_{2} \mathrm{Ca}_{n-1} \mathrm{Cu}_{n} \mathrm{O}_{4+2 n}$ where $n$ represents the number of the $\mathrm{CuO}_{2}$ layers in the unit cell. In all high- $T_{c}$ ceramic superconductors, the $\mathrm{CuO}_{2}$ planes which contain magnetic $\mathrm{Cu}^{2+}$ ions are supposed to enhance the superconductivity [6]. Due to the weak coupling between $\mathrm{BiO}-\mathrm{BiO}$ layers in the BSCCO system, it is easy to substitute different oxides for $\mathrm{Bi}^{3+}$. Although some of the results have demonstrated that there is no significant increase in the $T c$, it has been reported that important changes occur in the carrier concentration and critical current density due to different cation doping levels. It has been reported that the improvement of the critical current density due to the enhancement of trapped flux in the superconductor $[7,8]$ and single domain structure $[9,10]$. Similarly, the increase in the critical temperature is associated with the enhancement of average $\mathrm{Cu}$ valence. Moreover, doping has been also extensively studied in order to promote the formation of intragranular pinning centers or reduce weak links and, as a consequence, raise the electrical properties of this kind of materials [11-13].

Besides chemical doping, the synthetic methods have also been widely studied to produce high quality samples. Among these preparation techniques, some of them can be underlined, as the classical solid state [14,15] melt quench [16-19], sol-gel [20-23] and the polymer matrix [24-26] methods.

As it is well-known, from the crystallographic point of view and also from the transport one, high temperature superconductors possess a high anisotropy. Because of this anisotropy, grain orientation plays an important role on the transport properties. Therefore, texturing processes have been widely studied in order to improve the transport properties of BSCCO materials. When BSCCO materials are properly textured, their transport properties are improved in an important manner, compared with the non-textured materials. The texturing methods can be roughly divided into solid state methods, where the sample is maintained as a solid [27,28] and those where the sample is totally molten (directional solidification techniques). Among these last methods, the Laser Floating Zone (LFZ) one has been demonstrated to be an effective technique to produce a good grain orientation not only in Bi-2223 [15,29] and Bi-2212 [30,31] superconductors, but also in other anisotropic systems [32]. This method produces very high thermal gradients in the solidification front, producing a preferential alignment of grains with their c-axis perpendicular to the growth direction [33], maximizing the transport properties in the direction parallel to the growth axis. As it is well known, BSCCO superconductors show an incongruent melting, which makes necessary to perform annealing processes to produce the superconducting phase after a melt grown process [34]. The control of these annealing parameters would lead to the production of textured superconducting ceramics with high $\mathrm{J}_{\mathrm{c}}$ values together with a high degree of reproducibility. 
The aim of the present work is studying the effect of $\mathrm{Ce}$ substitution for $\mathrm{Ca}$ on the structural and superconducting properties of $\mathrm{Bi}-2212$ prepared by the conventional solid state method and then textured by LFZ technique.

\section{Experimental details}

$\mathrm{Bi}_{2} \mathrm{O}_{3}$ (98\%, Panreac), $\mathrm{SrCO}_{3}$ (98 + \%, Panreac), $\mathrm{CaCO}_{3}$ (98.5\%, Panreac), $\mathrm{CuO}(98 \%$, Panreac), and $\mathrm{CeO}_{2}(99.9 \%$, Aldrich) commercial powders were weighed in the stoichiometric ratios of $\mathrm{Bi}_{2} \mathrm{Sr}_{2} \mathrm{Ca}_{1-\mathrm{x}} \mathrm{Ce}_{\mathrm{x}} \mathrm{Cu}_{2} \mathrm{O}_{8+\delta}(\mathrm{x}=0,0.01,0.05,0.1$ and 0.25$)$. They were milled and calcined in air at $750{ }^{\circ} \mathrm{C}$ for 12 hours. After calcinations process, the mixture was re-ground for 1 hour and annealed uder air at $800{ }^{\circ} \mathrm{C}$ for another $12 \mathrm{~h}$. Then, the prereacted homogeneous powders were used to prepare cylindrical precursors, $120 \mathrm{~mm}$ long and $3 \mathrm{~mm}$ in diameter, approximately, by cold isostatic pressing with an applied pressure of $200 \mathrm{MPa}$ during 1 minute. The obtained cylinders were subsequently used as feed in a directional solidification process performed in a laser floating zone (LFZ) melting installation described schematically in previous works [35]. The bars have been processed using a continuous power Nd:YAG laser $(\lambda=1064 \mathrm{~nm})$, under air, at growth rate of $15 \mathrm{~mm} / \mathrm{h}$ and a relative rotation of $18 \mathrm{rpm}$ between seed and feed. After the texturing process, the samples were subjected to an annealing process consisting in two steps: $60 \mathrm{~h}$ at $860{ }^{\circ} \mathrm{C}$, followed by $12 \mathrm{~h}$ at $800{ }^{\circ} \mathrm{C}$ and, finally, quenched in air to room temperature in order to avoid oxygen overdoping which could negatively affect the $T_{c}$ values [36].

In order to identify the present phases in the textured materials, powder X-ray diffraction diagrams of the final products were recorded at room temperature using a Rigaku RadB powder diffractometer system working with $\mathrm{CuK} \alpha$ radiation and a constant scan rate between $2 \theta=3-60^{\circ}$ at room temperature. SEM micrographs were taken using a LEO Evo-40 VPX scanning electron microscope (SEM). Resistivity was measured by the standard four-probe method with silver paint contacts. Magnetic measurements were carried out in a 7304 model Lake Shore Vibrating Sample Magnetometer (VSM) system after cooling the sample in zero magnetic field (ZFC) between $\pm 10 \mathrm{kG}$ at four different temperatures; 10, 15, 20 and $25 \mathrm{~K}$. The samples with $\mathrm{x}$ $=0,0.01,0.05,0.1$ and 0.25 will be hereafter named as A, B, C, D and E, respectively.

\section{Results and discussion}

\subsection{XRD characterization}

Figure- 1 shows the normalized $[x$ (the normalised value $)=[a$ (the intensity value $)-a_{\min }$ (the minimum value obtained in the intensity) $] /\left[a_{\max }\right.$ (the maximum value obtained in the intensity)- $\left.\left.a_{\min }\right]\right]$ XRD diffraction patterns for the samples produced where the peaks for the Bi-2212 superconducting phase have been indicated. From these graphs, it can be seen both pure and Ce-doped samples contain the Bi-2212 phase as the major one, independently of the amount of the Ce doping. Moreover, small amounts of $\mathrm{CaCuO}_{2}$ nonsuperconducting secondary phase (indicated in Fig. 1 by *) can be detected in the samples. From these data, it is observed that the crystal symmetry of all the samples is tetragonal and the obtained lattice parameters are calculated using the least square method and then presented in Table 1 . As it can be inferred from these data, while $a-b$ parameters which are controlled by the length of in-plane $\mathrm{Cu}-\mathrm{O}$ bond are slightly 
increasing, c-parameter is decreasing with increasing Ce contents. It is argued that the variation of the oxygen content on the lattice structure by substituting $\mathrm{Ce}^{3+}$ for $\mathrm{Ca}^{2+}$ ions can cause the reduction in the $c$-parameter and, consequently, the raise in the $a-b$ parameters. In addition, no Ce-containing phase is observed, indicating that $\mathrm{Ce}$ atoms are incorporated into the crystal structure of Bi-2212 superconductor [37-39]. On the other hand, the XRD patterns are very similar for all the samples with only minor differences in the relative intensity for some diffraction which can be produced by an induced orientation of the plate-like grains in the samples preparation for the XRD diffraction experiments.

\subsection{SEM analysis}

Figure-2 shows SEM images corresponding to the longitudinal polished surface of samples after annealing. The different contrasts seen in SEM micrographs imply that there are different phases in the structure. From these micrographs, it is evident that all samples predominantly have Bi-2212 phase together with some minor secondary phases. Light grey phase (marked as \#1) in Fig.2 shows a composition close to the ideal Bi-2201 stoichiometry. On the other hand, small black spots (marked as \#2) have been identified as $\mathrm{CaO}$ particles, which are randomly spread in the samples. The phase marked as \#3 (dark grey contrast) belongs to the Bi-free primary solidification phase. These phases are generally formed from the phases of $\left(\mathrm{Ca}_{1-x} \mathrm{Sr}_{x}\right) \mathrm{CuO}_{2}$. It is well known that high-temperature phases in Bi-based superconductor occur while the contrasts of samples are getting darker in Bi- based superconductors. Thus, grey phase (marked as \#4) corresponds to the Bi-2212 phase which is also determined by EDX. These results show that the performed process has been adequate in the preparation of samples when taking into account that the $\mathrm{Bi}-2212$ superconducting phase proportion in the samples is high.

\subsection{Electrical measurements}

The normalized electrical resistance versus temperature curves for all the samples, from $300 \mathrm{~K}$ down to $25 \mathrm{~K}$ are given in Fig. 3. It is found that all the samples show metallic behavior below room temperature value followed by a superconducting transition when the temperature is decreased. In addition, all samples show a broad transition at around the transition temperatures which can imply the presence of impurities and weak links between superconducting grains [40]. Consequently, the $T_{c}{ }^{\text {offset }}$ values, responsible for superconductivity, are found to be considerably shifted and decreased with the increase of Ce contents. On the other hand, the superconducting transition of all the samples is composed of only one-step transition, indicating that only Bi-2212 phase is present in the matrix. These results are also supporting XRD results discussed previously. The onset and offset critical transition temperatures of the samples, together with the superconducting transition range $(\Delta T)$ are displayed in Table 1. The onset critical $\left(T_{c}^{\text {onset }}\right)$ and offset critical $\left(T_{c}^{\text {offset }}\right)$ temperatures obtained from the normalized resistance graph versus Ce-content are shown in Fig.4. It can be easily seen that both critical temperatures gradually decrease with the increase of Ce amount.

\subsection{Carrier concentration calculation}

The number of holes, $\mathrm{p}$, per $\mathrm{Cu}$ atom can be calculated by using the relation 


$$
\frac{T_{c}}{T_{c}^{\max }}=1-82.6(p-0.16)^{2}
$$

given by Presland et al. [41], where $T_{c}^{\max }$ is taken as $85 \mathrm{~K}$ for the Bi-2212 system and $T_{c}^{\text {offset }}$ values are taken from Table 1. The results obtained show that the p-values of the samples are ranging from 0.144 to 0.092 and can be observed in Table 1. The number of the hole-carrier concentrations is in agreement with the results of Bal et.al. [42]. The variation of hole-concentration as a function of Ce-content is plotted in Fig.5. In the figure, it is clear that the hole-concentration decreases with increasing Ce substitution. It is due to the $\mathrm{Ce}$ substitution which reduces the number of holes per $\mathrm{Cu}$ atom and destroys the superconducting properties of the system.

\subsection{Magnetic properties}

The hysteresis curves of the samples have been measured at four different temperatures $10,15,20$ and $25 \mathrm{~K}$. All those hysteresis loops were obtained after cooling the sample in zero magnetic fields (ZFC) and measured between the fields of $\pm 10 \mathrm{kG}$. Typical examples of magnetic hysteresis loops of the samples for the temperatures 10 and $25 \mathrm{~K}$ are presented in Figs. 6 and 7, respectively. The general behavior of hysteresis loops shown in these figures indicates that there is a dependence of magnetization values with the amount of $\mathrm{Ce}$. The magnetization values decrease when the amount of $\mathrm{Ce}$ is increased. In addition, the volume of the closed hysteresis curves is decreased gradually with increasing $\mathrm{Ce}$ concentration. This is an indication that the superconducting properties related to the magnetic properties of the system start to be negatively affected due to the increase of $\mathrm{Ce}$ concentration, in agreement with previously discussed observations.

Figure 8 shows the magnetization as a function of temperature (M-T) curve which gives intragrain $T_{c}$ values with the currents circulating inside the grains due to the weak links between grains [43]. It can be observed that all samples display a typical diamagnetic bahavior. On the other hand, the diamagnetic signal and the critical temperature, $\mathrm{T}_{\mathrm{c}}$, values decrease and shift towards lower temperatures with increasing Ce substitution. The values of the critical temperatures found from the starting point of diamagnetic behavior are $86.93,86.80,86.13,85.75,82.15$, respectively. From this graphic it is clear that the best results are obtained for the sample A which is pure one, confirming the observations made in the hysteresis loops and discussed previously. This result indicate that the oxygen content in all the samples is approximately the same, as $T_{c}$ is very sensitive to the $\delta$ value in the general formula $\mathrm{Bi}_{2} \mathrm{Sr}_{2} \mathrm{CaCu}_{2} \mathrm{O}_{8+\delta}$ [44]

The $\mathrm{J}_{\mathrm{c}}$ values of the samples were calculated from the hysteresis loop data obtained at different temperatures, 10, 15, 20 and $25 \mathrm{~K}$, using the Bean's model [45].

$$
\mathrm{J}_{\mathrm{c}}=30 \frac{\Delta M}{d}
$$

where $\mathrm{J}_{\mathrm{c}}$ is the magnetization current density in ampéres per square centimeter of a sample. $\Delta M=M_{+}-M_{-}$is measured in electromagnetic units per cubic centimeter, $\mathrm{d}$ is the thickness of sample. For clarity, in Fig. 9 it is only shown the calculated critical current densities for all the samples, as a function of the applied field, at $10 \mathrm{~K}$, taking into account that the evolution of the samples has been the same in all the measured temperatures. As can be seen from the figure, $J_{c}$ values gradually decrease with the increasing magnetic field and Ce values. The field dependence of $\mathrm{J}_{\mathrm{c}}$ can be related to the 
presence of structural defects or the weak links between grains, typical feature in ceramic superconductors.

\section{CONCLUSIONS}

In this study, the effect of $\mathrm{Ce}$ substitution for $\mathrm{Ca}$ on the structural and superconducting properties of $\mathrm{Bi}-2212$ prepared by conventional solid state method and then textured by LFZ technique has been studied. From XRD diffraction pattern, nearly single Bi-2212 phase has been obtained, independently of the amount of Ce. The SEM micrographs confirm that all samples are predominantly composed by the Bi-2212 phase in all cases. $\mathrm{R}-\mathrm{T}$ results indicated that all samples behave metallically, below room temperature followed by a superconducting transition as the temperature is still decreased. In addition, all samples showed a broad transition from the normal to the superconducting state, pointing out the presence of impurities and weak links between superconducting grains. From $\mathrm{M}-\mathrm{H}$ measurements, it was found that the magnetization values and the volume of the closed hysteresis curves decrease with increasing of Ce-content. $J_{c}$ values calculated from the hysteresis loop measurement by using Bean's model, showed a parallel behavior.

\section{Acknowledgement}

This work is supported by Research Fund of Çukurova University, Adana, Turkey, under grant contracts no: FEF2011YL27. A. Sotelo and M. A. Madre wish to thank the Gobierno de Aragón (Research Group T12), the Spanish Ministry of Science and Innovation-FEDER (Project MAT2008-00429), and the Universidad de ZaragozaIbercaja (Project UZ2011-TEC-03) for financial support. M. A. Madre also acknowledges the MINECO-FEDER (Project MAT2011-22719) for funding.

\section{References:}

1. C. Michel, M. Hervieu, M. Borel, A. Grandin, F. Deslandes, J. Provost, B. Raveau, Z. Phys. B 68, 421 (1987)

2. H. Maeda, Y. Tanaka, M. Fukutomi, T. Asano, Jpn. J. Appl. Phys. 27, L209 (1988)

3. A. I. Abou-Aly, M. M. H. Abdel Gawad, R. Awad, I. G-Eldeen, J. Supercond. Nov. Magn. 24, 2077 (2011)

4. M. Cyrot, D. Pavuna, Introduction to Superconductivity and High-Tc Materials. Word Scientific, Singapore 249 (1995)

5. Y. B. Huang, G. F. de la Fuente, A. Sotelo, M. T. Ruiz, A. Larrea, L. A. Angurel, R. Navarro, Solid State Ionics 889, 63 (1993)

6. P.W. Anderson, Science 235, 1196 (1987)

7. Y. Ren, R. Weinstein, J. Liu, R.P. Sawh, C. Foster, Physica C 251, 15 (1995)

8. H. Ikuta, A. Mase, Y. Yanagi, M. Yoahikawa, Y. Itoh, T. Oka, U. Mizutani, Supercond. Sci. Technol. 11, 1345 (1998) 
9. X.Q. Xu, Y.Q. Cai, C.X. Yang, X. Yao, S. Xu, A. Kortyka, R. Puzniak, Supercond. Sci. Technol. 22, 015001 (2009)

10. Xu, Y., Izumi, M., Tsuzuki, K., Zhang, Y.F., Xu, C.X., Murakami, M., Sakai, N., Hirabayashi, I.: Supercond. Sci. Technol. 22, 095009 (2009)

11. M. A. Madre, H. Amaveda, M. Mora, A. Sotelo, L. A. Angurel, J. C. Diez, Bol. Soc. Esp. Ceram. V. 47, 148 (2008)

12. A. Sotelo, M. A. Madre, Sh. Rasekh, J. C. Diez, L. A. Angurel, Adv. Appl. Ceram. 108,285 (2009)

13. A. Sotelo, M. Mora, M. A. Madre, J. C. Diez, L. A. Angurel, G. F. de la Fuente, J. Eur. Ceram. Soc. 25, 2947 (2005)

14. N. Knauf, J. Harwischmacher, R. Miller, R. Borowski, B. Rodeu, D. Wohllebreu, Physica C 173, 414 (1991)

15. M. F. Carrasco, F. M. Costa, R. F. Silva, F. Gimeno, A. Sotelo, M. Mora, J. C.

Diez, L. A. Angurel, Physica C 415, 163 (2004)

16. S. Elschner, J. Boch, G. Brommer, P. Hermann, IEEE Trans. Magn. 21, 2724 (1996)

17. A. Coskun, A. Ekicibil, B. Ozcelik, Chin.Phys.Lett. 19/12, 1863 (2002)

18. D. Yazıcı, B. Ozçelik, M.E. Yakıncı, J. Low Temp. Phys. 163, 370 (2011)

19. B. Ozkurt, A. Ekicibil, M.A. Aksan, B. Ozçelik, M.E. Yakıncı, K. Kiymac, J. Low Temp. Phys. 149, 105 (2007)

20. C. J. Huang, T.Y. Tseng, T. S. Heh, F. H. Chen, W. S. Jong, Y. S. Fran, S. M. Shiau, Solid State Commun. 72, 563 (1989)

21. R.S. Liu, W.N. Wang, C.T. Chang, P.T. Wu, Jpn. J. Appl. Phys. 28, L2155 (1989)

22. T. Asaka, Y. Okazawa, T. Hirayama, K. Tachikawa, Jpn. J. Appl. Phys. 29, L280 (1990)

23. M. Mora, A. Sotelo, H. Amaveda, M. A. Madre, J. C. Diez, L. A. Angurel, G. F. de la Fuente, Bol. Soc. Esp. Ceram. V. 44, 199 (2005)

24. A. Sotelo, G. F. de la Fuente, F. Lera, D. Beltran, F. Sapiña, R. Ibañez, A. Beltran, M. R. Bermejo, Chem. Mater. 5, 851 (1993)

25. A. Sotelo, H. Szillat, P. Majewski, F. Aldinger, Supercond. Sci. Technol. 10, 717 (1997)

26. A. Sotelo, J. I. Peña, L. A. Angurel, J. C. Diez, M. T. Ruiz, G. F. de la Fuente, R. Navarro, J. Mater. Sci. 32, 5679 (1997)

27. V. Garnier, R. Caillard, A. Sotelo, G. Desgardin, Physica C 319, 197 (1999) 
28. S. Marinel, D. Bourgault, O. Belmont, A. Sotelo, G. Desgardin, Physica C 315, 205 (1999)

29. Y. B. Huang, G. F. de la Fuente, A. Sotelo, A. Badia, F. Lera, R. Navarro, R.

Ibañez, D. Beltran, F. Sapiña, A. Beltran, Physica C 185-189, 2401 (1991)

30. A. Sotelo, M. A. Mora, H. Amaveda, J. C. Diez, L. A. Angurel, M. C. Mayoral, Bol. Soc. Esp. Ceram. V. 45, 228 (2006)

31. B. Özkurt, M. A. Madre, A. Sotelo, M.E. Yakıncı, B. Özçelik, J. Supercond. Nov. Magn. 25, 799 (2012)

32. A. Sotelo, E. Guilmeau, M. A. Madre, S. Marinel, J. C. Diez, M. Prevel, J. Eur.

Ceram. Soc. 27, 3697 (2007)

33. G. F. de la Fuente, M. T. Ruiz, A. Sotelo, A. Larrea, R. Navarro, Mater. Sci. Eng. A 173, 201 (1993)

34. A. Sotelo, M. A. Madre, J. C. Diez, Sh. Rasekh, L. A. Angurel, E. Martinez, Supercond. Sci. Technol. 22, 034012 (2009)

35. G. F. de la Fuente, A. Sotelo, Y. Huang, M. T. Ruiz, A. Badia, L. A. Angurel, F.

Lera, R. Navarro, C. Rillo, R. Ibañez, D. Beltran, F. Sapiña, A. Beltran, Physica C 509, $185(1991)$

36. G. Triscone, J.Y. Genoud, T. Graf, A. Junod, J. Muller, Physica C 176, 247 (1991)

37. S. Vinu, P.M. Sarun, A. Biju, R. Shabna, P. Guruswamy, U. Syamaprasad, Supercond. Sci. Technol. 21, 045001 (2008)

38. S. Vinu, P.M. Sarun, R. Shabna, A. Biju, U. Syamaprasad, Mater.Lett. 62, 4421 (2008)

39. R. Shabna, P.M. Sarun, S. Vinu, A. Biju, U. Syamaprasad, Supercond.Sci. Technol. 22, 045016 (2009)

40. A. Ianculescu, M. Gartner, B. Despax, V. Bley, Th. Lehy, R. Gayrila, M.

Modreanu, Appl.Surf.Sci. 253, 344 (1996)

41. M.R. Presland, J.L. Tallon, R.G. Buckley, R.S. Liu, N.E. Floer, Physica C 176, 95 (1991)

42. S. Bal, M. Dogruer, G. Yıldırım, A. Varilci, C. Terzioglu, Y. Zalaoglu, J.

Supercond. Nov. Magn. 25, 847 (2012)

43. U. Topal, M.E. Yakınc1, Materials Chemistry and Physics. 119, 182 (2010)

44. G. Triscone, J.Y. Genoud, T. Graf, A. Junod, J. Muller, Physica C 176, 247 (1991)

45. C.P. Bean, Phys. Rev. Lett. 8, 250 (1962) 
Table 1. $T_{c}$ values deduced from the $R-T$ measurement data, unit cell parameters and hole-carrier concentration for each of the samples

\begin{tabular}{|l|l|l|l|l|l|}
\hline Samples & $T_{c}(\mathrm{~K})$ & $\Delta T(\mathrm{~K})$ & $\begin{array}{l}\text { Unit-cell } \\
\text { parameter } \\
a=b(\AA)\end{array}$ & $\begin{array}{l}\text { Unit-cell } \\
\text { parameter } \\
c(\AA)\end{array}$ & $\begin{array}{l}\text { Hole } \\
\text { Concentration } \\
(p)\end{array}$ \\
\hline $\mathbf{A}$ & $\begin{array}{l}\mathbf{T}_{\text {c.onset }}=\mathbf{1 0 5 K} \\
\mathbf{T}_{\text {c.offset }}=\mathbf{9 0 . 2 K}\end{array}$ & $\mathbf{1 4 . 8}$ & $\mathbf{3 . 8 2 0}$ & $\mathbf{3 0 . 9 5}$ & $\mathbf{0 , 1 4 4}$ \\
\hline $\mathbf{B}$ & $\begin{array}{l}\mathbf{T}_{\text {c.onset }}=\mathbf{1 0 1 K} \\
\mathbf{T}_{\text {c.offset }}=\mathbf{8 6 K}\end{array}$ & $\mathbf{1 5}$ & $\mathbf{3 . 8 2 4}$ & $\mathbf{3 0 . 9 1}$ & $\mathbf{0 , 1 3 1}$ \\
\hline $\mathbf{C}$ & $\begin{array}{l}\mathbf{T}_{\text {c.onset }}=\mathbf{9 3 K} \\
\mathbf{T}_{\text {c.offset }}=\mathbf{8 5 . 1 K}\end{array}$ & $\mathbf{7 . 9}$ & $\mathbf{3 . 8 2 9}$ & $\mathbf{3 0 . 9 0}$ & $\mathbf{0 , 1 2 9}$ \\
\hline $\mathbf{D}$ & $\begin{array}{l}\mathbf{T}_{\text {c.onset }}=\mathbf{9 3 K} \\
\mathbf{T}_{\text {c.offset }}=\mathbf{8 2 K}\end{array}$ & $\mathbf{1 1}$ & $\mathbf{3 . 8 3 2}$ & $\mathbf{3 0 . 8 9}$ & $\mathbf{0 , 1 2 3}$ \\
\hline $\mathbf{E}$ & $\begin{array}{l}\mathbf{T}_{\text {c.onset }}=\mathbf{8 7 K} \\
\mathbf{T}_{\text {c.offset }}=\mathbf{5 7 K}\end{array}$ & $\mathbf{3 0}$ & $\mathbf{3 . 8 3 4}$ & $\mathbf{3 0 . 8 8}$ & $\mathbf{0 , 0 9 2}$ \\
\hline
\end{tabular}




\section{Figure captions}

Figure 1. XRD patterns of the A, B, C, D and E samples. Peaks corresponding to the Bi-2212 and $\mathrm{CaCuO}_{2}$ phases are indicated by + and *, respectively

Figure 2. SEM micrographs performed on longitudinal polished sections of the different samples.

Figure 3. Resistivity as a function of temperature curves for all the samples

Figure 4. $T_{c}^{\text {onset }}$ and $T_{c}^{\text {offset }}$ values versus Ce-content.

Figure 5. Variation of hole-carrier concentration versus Ce-content.

Figure 6. $\mathrm{M}-\mathrm{H}$ curves for all samples measured at $10 \mathrm{~K}$.

Figure 7. M-H curves for all samples measured at $25 \mathrm{~K}$.

Figure 8. Magnetic moment versus temperature for all samples.

Figure 9. Calculated critical current densities, $J_{c}$, of the samples, as a function of applied field, at $10 \mathrm{~K}$. 
Figure 1

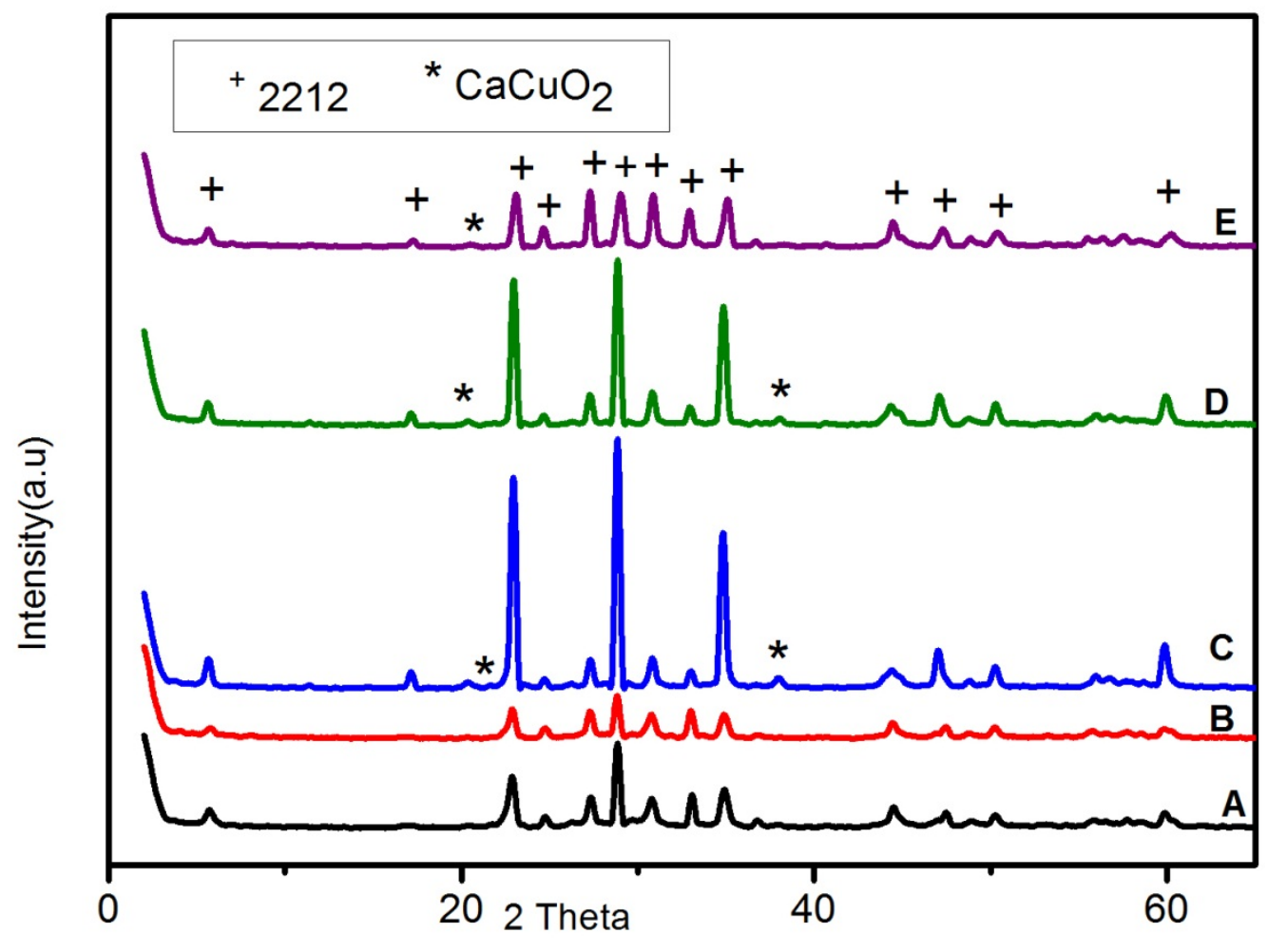




\section{Figure 2}
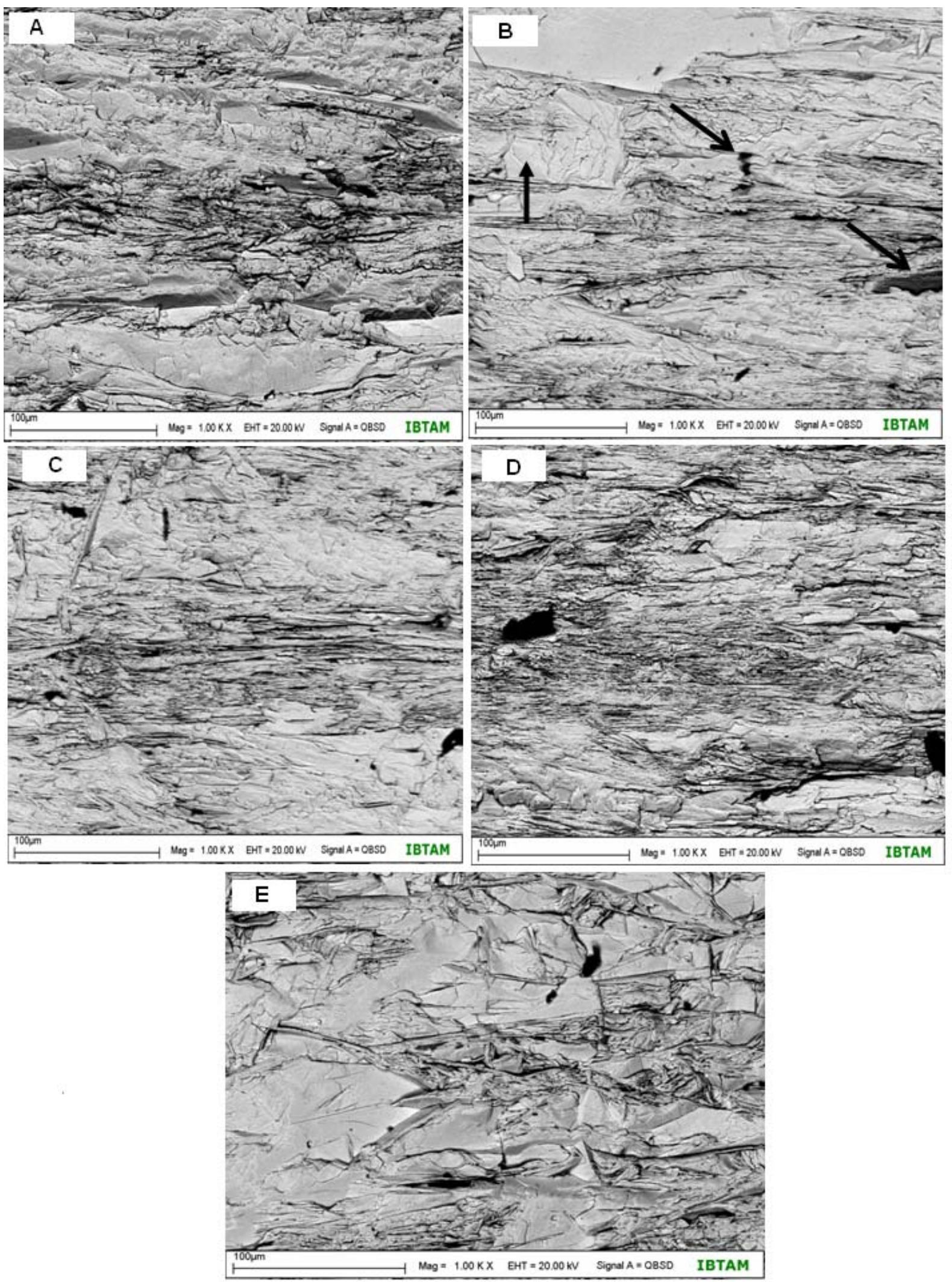
Figure 3

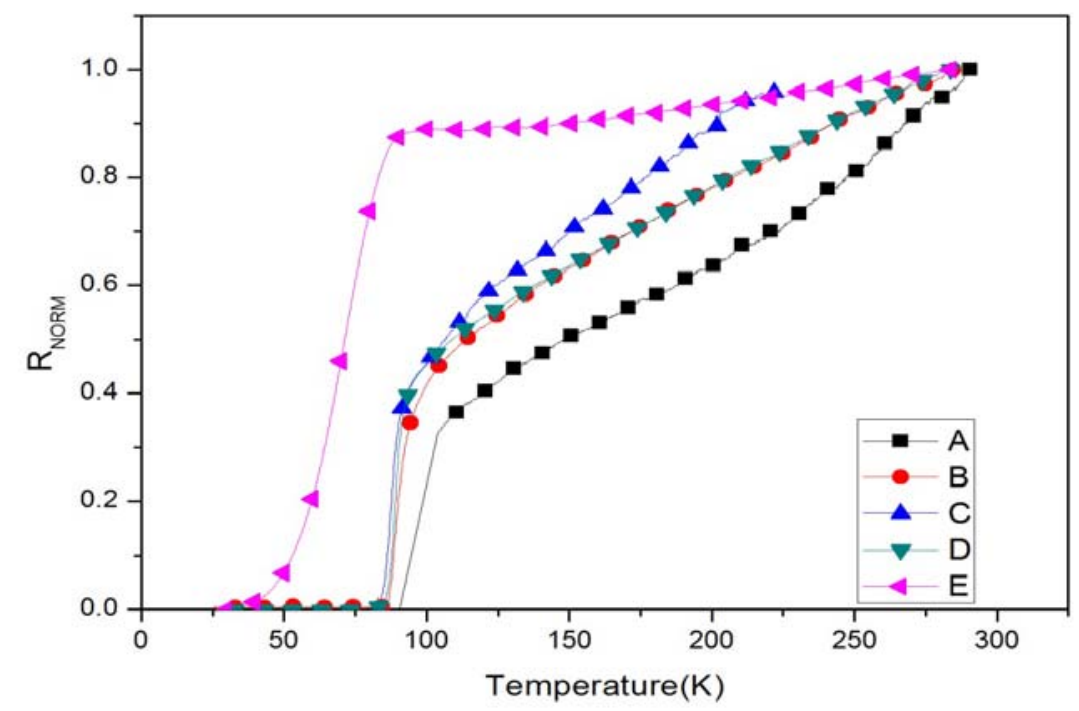


Figure 4

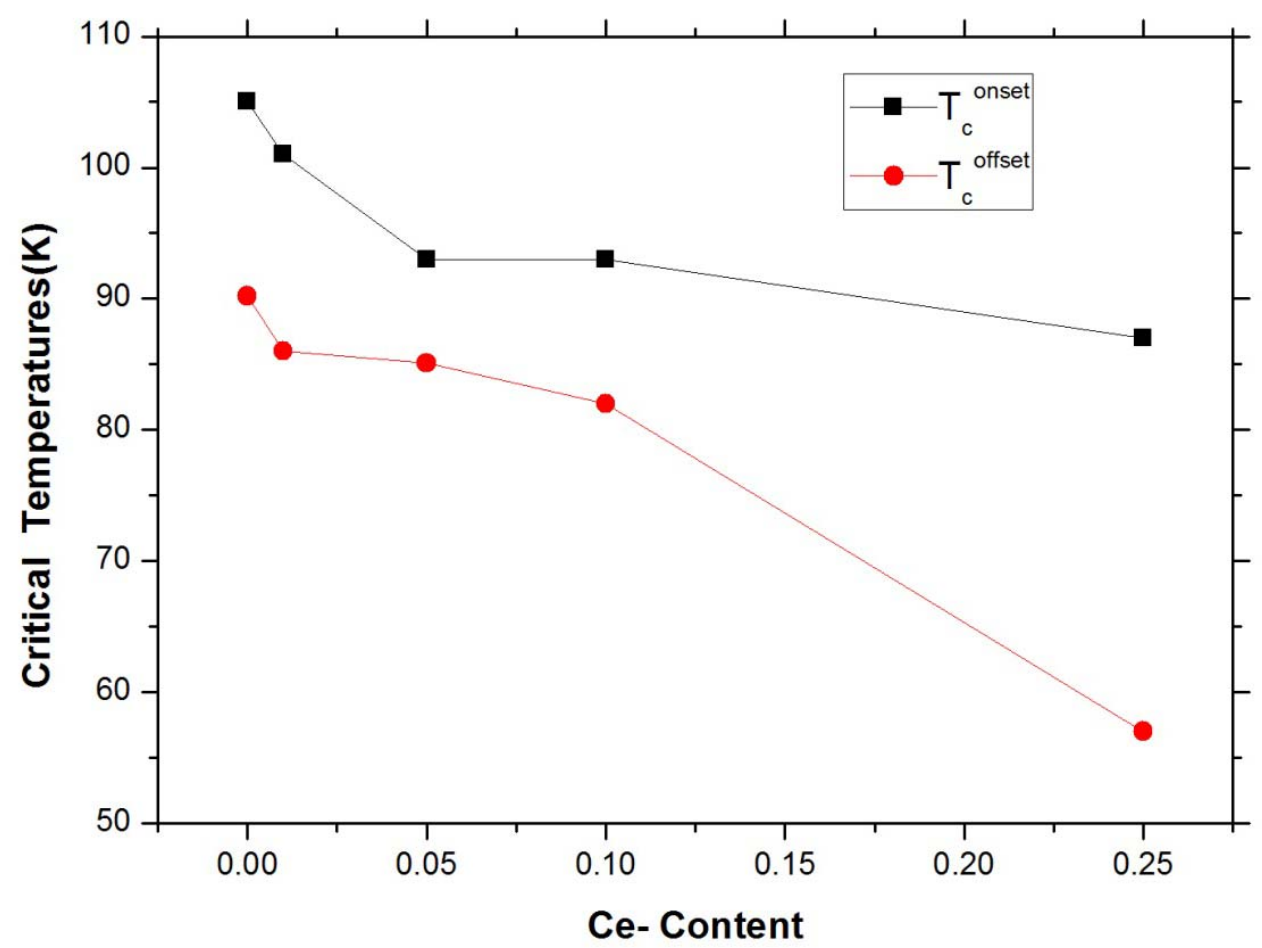


Figure 5

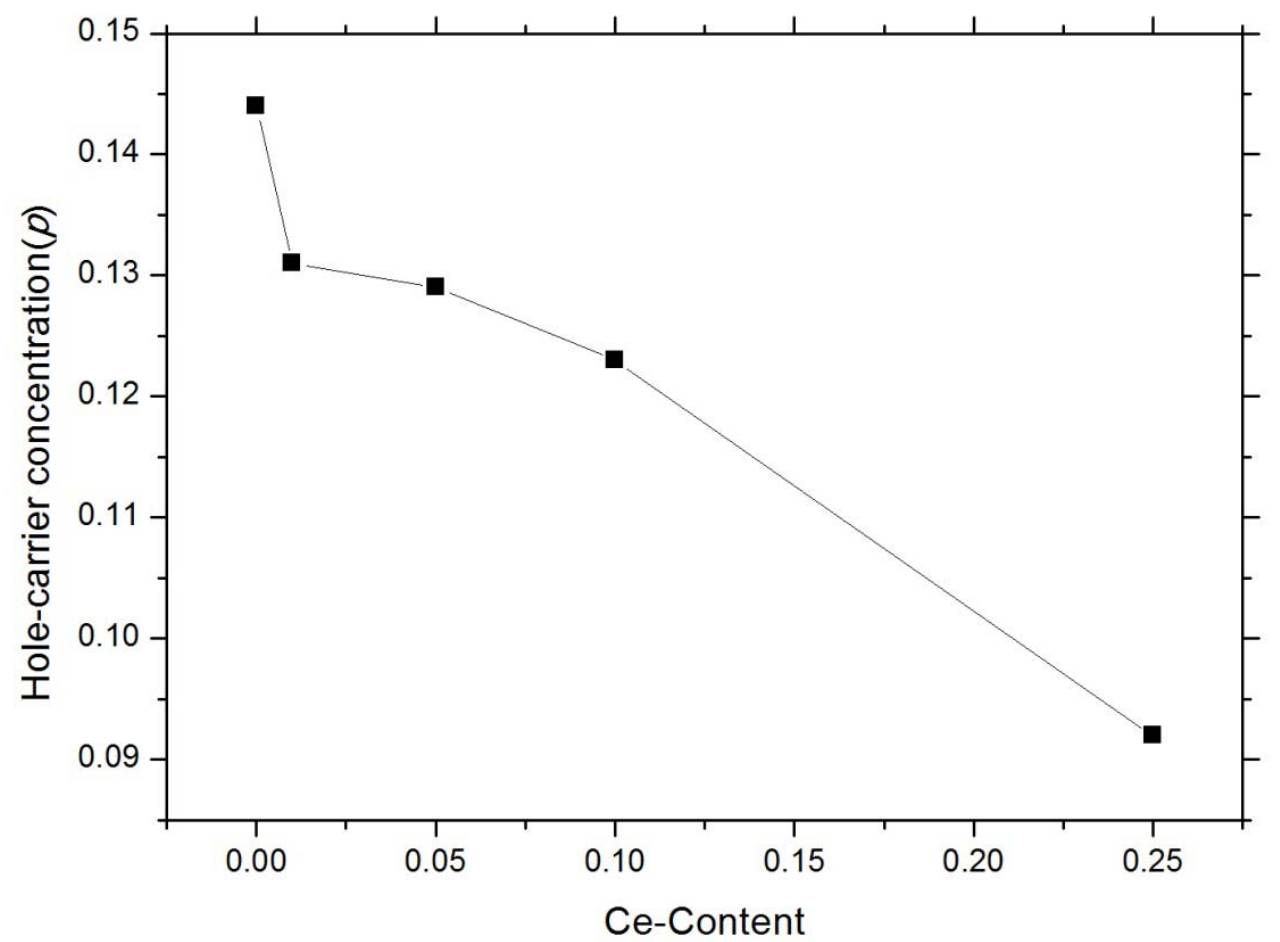


Figure 6

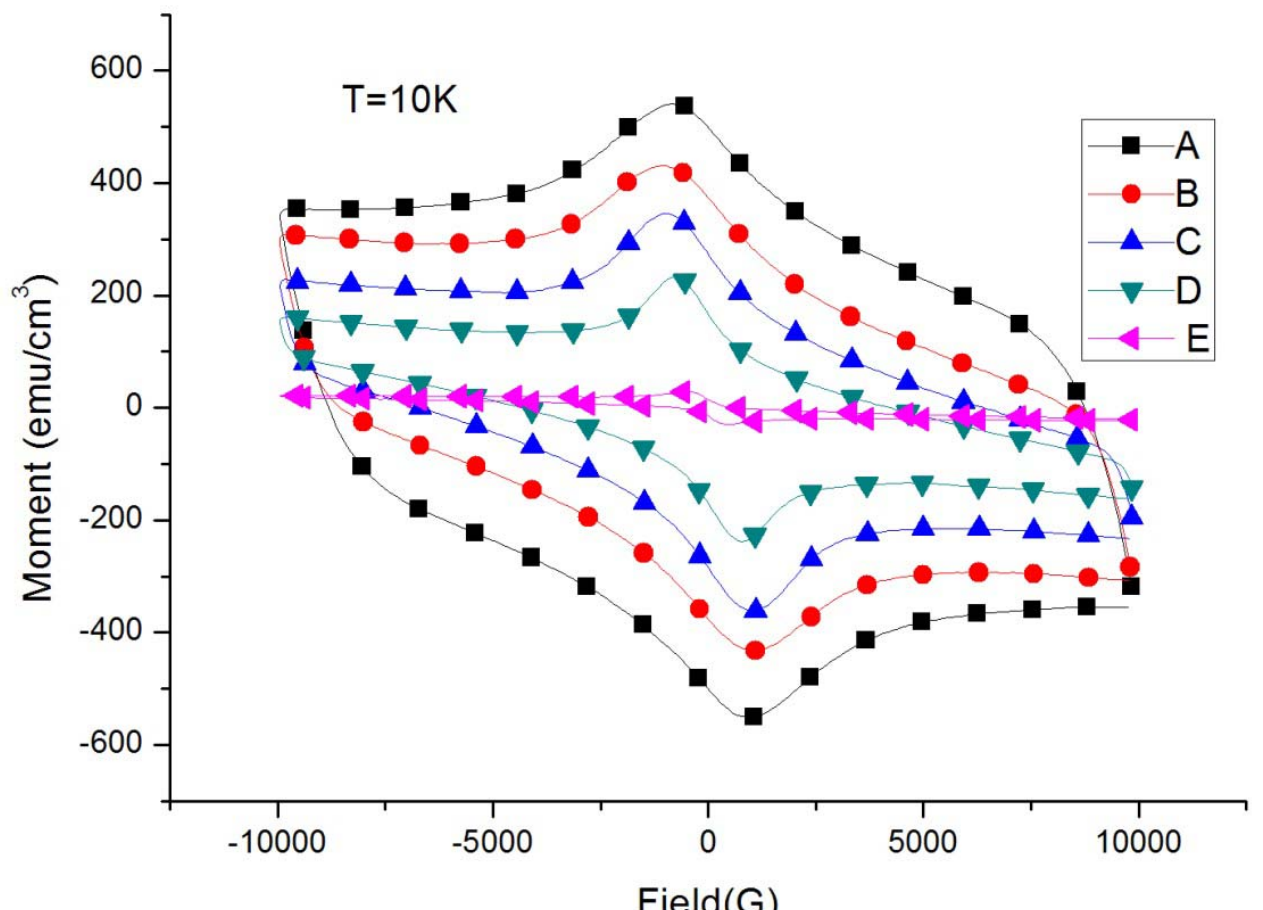

Field(G) 
Figure 7

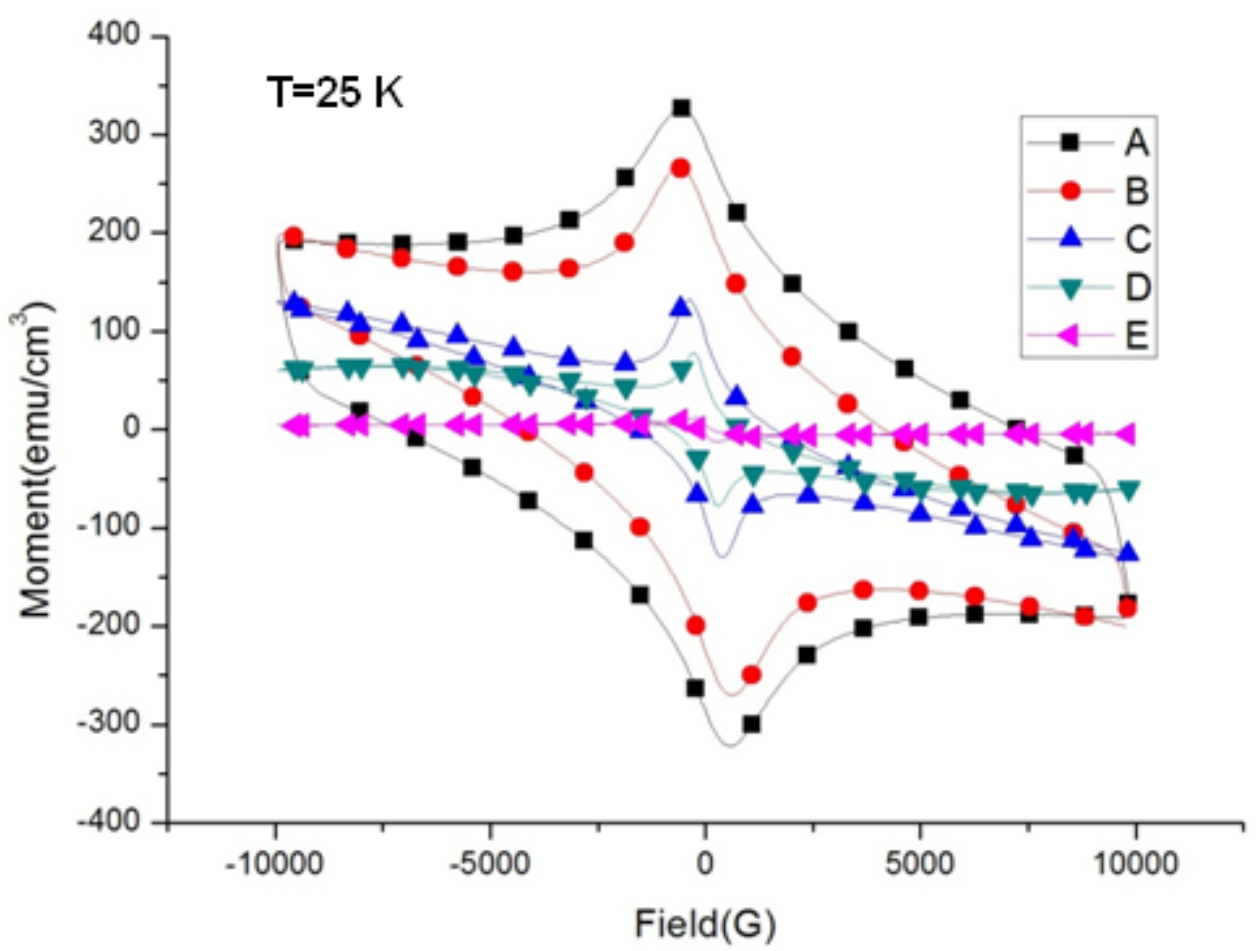


Figure 8

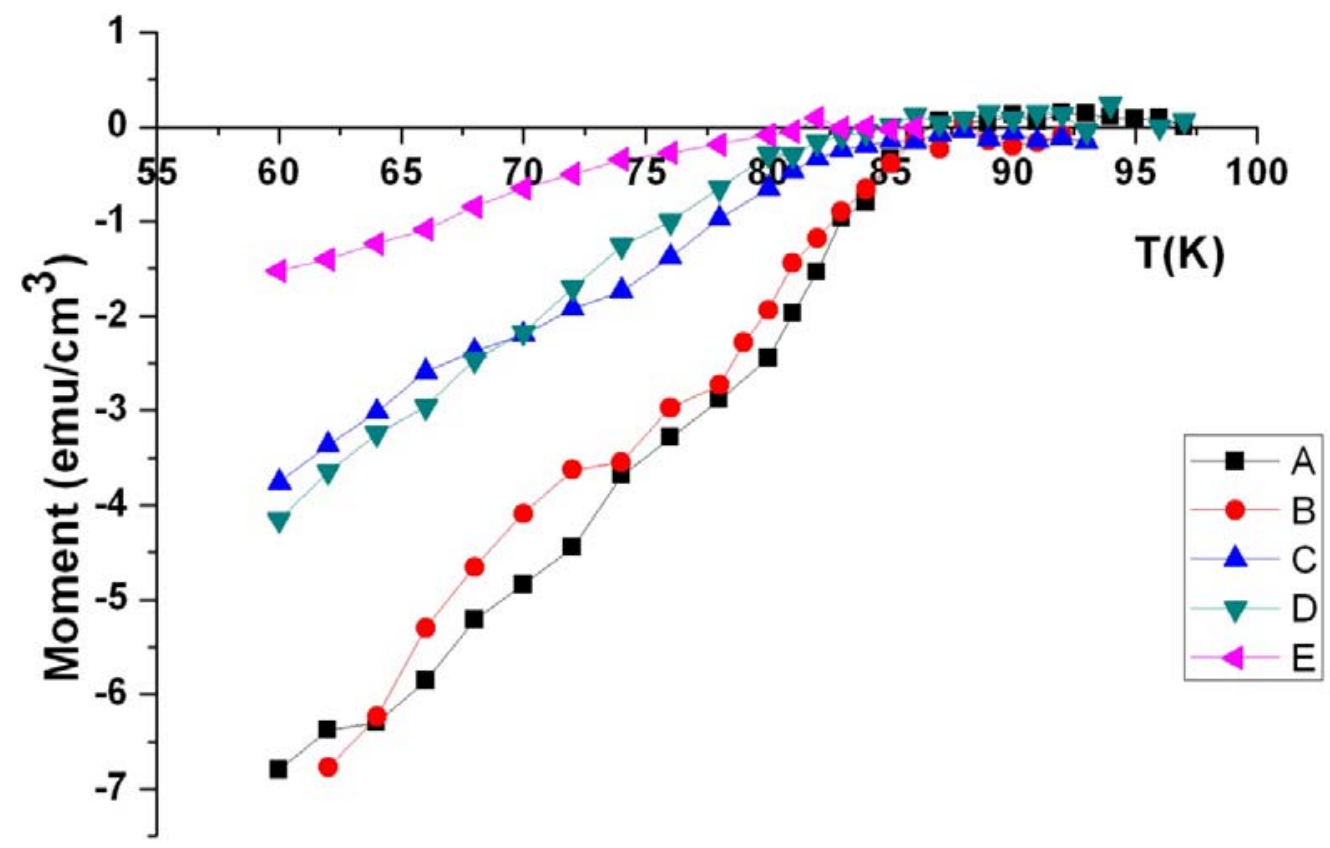


Figure 9

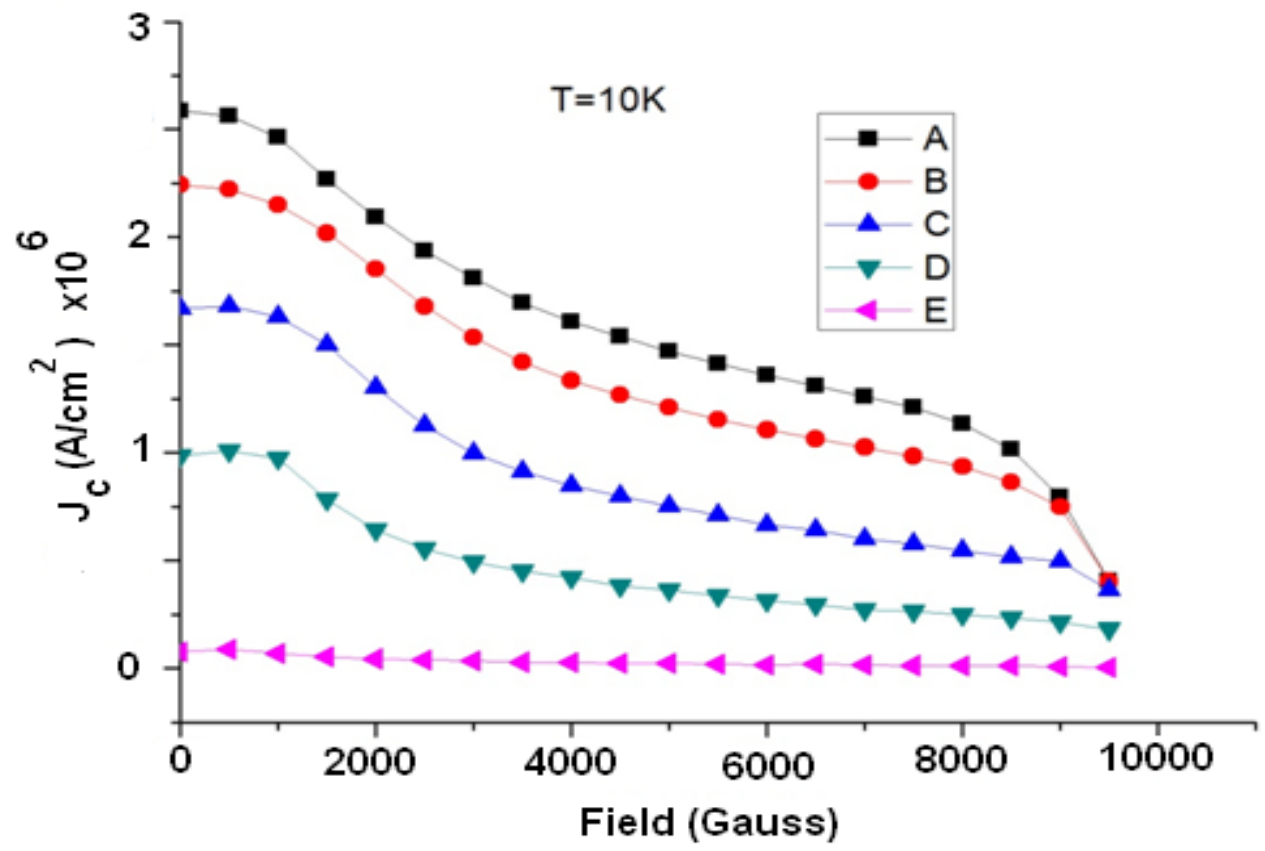

